\title{
Improving early detection of exotic or emergent oyster diseases in France: identifying factors associated with shellfish farmer reporting behaviour of oyster mortality
}

\author{
C. Lupo ${ }^{a, *}$, A. Osta Amigo ${ }^{a}$, Y.V. Mandard ${ }^{b}$, C. Peroz ${ }^{c, d}$, T. Renault ${ }^{a}$
}

\footnotetext{
a Ifremer-SG2M-LGPMM Laboratoire de Génétique et Pathologie des Mollusques Marins-Avenue Mus de Loup, 17390 La Tremblade, France

${ }^{\mathrm{b}}$ DDTM17 - Departmental Direction for Territories and Sea - 89 avenue des cordeliers, 17018 La Rochelle cedex, France

${ }^{c}$ LUNAM Université, Oniris, Ecole nationale vétérinaire, agroalimentaire et de l'alimentation Nantes-Atlantique, UMR Biologie, Epidémiologie et Analyse de Risque en santé animale, BP 40706, F-44307 Nantes, France

d INRA, UMR1300, F-44307 Nantes, France
}

*: Corresponding author : C. Lupo, tel.: +33 546762610 ; fax: +33 546762611 ; email address : clupo@ifremer.fr

\begin{abstract}
:
Farmers' vigilance is essential for the detection of epidemics, including potential emerging diseases, in marine shellfish. A field study was conducted to investigate oyster farmers' reporting practices and behaviour, and to identify factors influencing the reporting process of oyster mortality, with the ultimate aim of improving early detection of unexplained oyster mortality outbreaks.
\end{abstract}

A retrospective case-control study of oyster farmers from Charente-Maritime (France) was designed, based on interviews with 27 non-reporting and 89 reporting farmers, further split into 40 formerlyreporting and 49 currently-reporting farmers. Information about farmer and farm characteristics, farming practices, farm health history and related financial compensation on the farm, knowledge of the mortality reporting system and reporting behaviour was collected. Sampling design was considered in the calculations and farmers' reporting behaviour was modelled using an ordinal logistic regression (continuation-ratio model).

Notification procedures were fairly well known among farmers and the reporting system was well accepted overall. Nevertheless, a lack of awareness of the aims of the reporting system was revealed, which contributed to late reporting. Factors identified as driving a farmer's decision to report oyster mortality concerned their lack of awareness of mortality reporting (production type, farm size, location of the production cycle, accessibility of the leasing grounds) and willingness to report (possibility and extent of financial compensation, a feeling of not being involved, whether it was first year of reporting). Overall classification performance of the model built in this study was $64 \%$. In particular, financial compensation for oyster production losses appeared to be a clear incentive for reporting, but was countered by a habituation effect combined with a lack of awareness of the aims of the reporting system: oyster farmers looking for benefits for themselves in reporting, rather than early detection of a disease outbreak. 
Both economic compensation and the farmers' non-economic values and perceptions should be considered to improve oyster farmers' reporting compliance and sustainability of the reporting system. Education and participatory approaches could help to change these attitudes and thus improve oyster farmers' compliance with reporting duties, resulting in improved early detection of epidemics and emerging or exotic oyster diseases.

\section{Highlights}

Oyster farmers' reporting practices and behaviour towards oyster mortality were investigated. Notification procedures were fairly well known. A lack of awareness of the aims of the reporting system was revealed, contributing to late reporting. Both economic and non-economic factors were identified as drivers for farmer reporting decision.

Keywords : Case-control study ; Ordinal logistic regression ; Surveillance ; Notification ; Shellfish diseases 


\section{Introduction}

64

In France, the current surveillance system for marine mollusc health is mainly based on the observation of any increased shellfish mortality by shellfish farmers and its immediate mandatory notification to the local competent authority (European Union, 2006; French Ministry of Agriculture, 2008). But, although immediate notification of any observed mortality event is mandatory, the current definition of an increased shellfish mortality does not include objective criteria and mortality estimation is not straightforward: " increased mortality' means unexplained mortalities significantly above the level of what is considered to be normal for the [...] mollusc farming area in question under the prevailing conditions. What is considered to be increased mortality would be decided in cooperation between the farmer and the competent authority" (European Union, 2006). Shellfish farmers have to complete a standardized notification sheet (French Ministry of Agriculture, 2010a). This mandatory document is a pre-tabulated paper form, which is filled in (usually by handwriting) by the farmer. This form has to be immediately transmitted to the local competent authority. The national mollusc disease surveillance network (Repamo) then becomes involved, for anamnesis and laboratory diagnosis based on biological samples (Dufour and Hendrickx, 2009).

81 This system notably aims to early detect the appearance of any exotic or emerging pathogen 82 in the territorial waters. Indeed, as diseased shellfish seldom show symptoms, any 83 unexplained mortality is a potential indicator for pathogen introduction or emergence. This was well illustrated in 2008 , when mortality notification data represented one of the rare data sources that both acted as an alert and described the extent of the mass mortality outbreaks 
87 associated with the detection of a newly described genotype ( $\mu$ Var) of the Ostreid herpesvirus

88 (OsHV-1) (European Food Safety Agency, 2010; Segarra et al., 2010). Unfortunately, this

89 infection has become endemic (Lupo et al., 2011b), showing that control of the spread of this 90 emerging pathogen has failed.

91 Early detection of pathogen introduction or emergence in shellfish is crucial, as openness and connectivity of marine systems enable rapid disease spread (McCallum et al., 2004) and successful control of disease is very unlikely once established in shellfish populations (Lupo et al., 2012a). The use of drugs is not possible; therapeutic levels cannot be obtained economically or without unacceptable environmental impacts. Vaccination cannot be used because shellfish lack a true adaptive immune system, relying totally on their innate immune system to overcome diseases (Renault, 2009). However, there exists a window of opportunity to limit spread, which would need to be done mainly by restricting shellfish movements (European Union, 2006), and possibly by eliminating a pathogen early in an epidemic.

Like in any animal health surveillance system relying on the reporting of suspicious events,

102 shellfish farmers are the best placed to inquire into and notify authorities of any suspicion of 103 disease in the field (Dufour and Hendrickx, 2009). Their active involvement in this 104 surveillance system is fundamental to make it effective, i.e. sensitive and timely to provide 105 early alerts. However, a recent study has shown that participation of French oyster farmers in 106 the mortality notification system was not sustained over the 2007-2010 time period (Lupo et 107 al., 2012b). Since 2010, financial incentives have been implemented, with mortality 108 notification becoming mandatory to qualify for financial compensation (French Ministry of 109 Agriculture, 2010b). It is necessary to identify the incentives and barriers to the farmers' 110 participation in the surveillance system in order to design an improved means of reporting

111 (World Bank, 2010) and to help sustain farmers' motivation to report. 
113 A few studies have investigated the reasons for farmer under-reporting diseases in livestock

114 (Limon et al., 2013), cattle (Palmer, 2009; Bronner et al., 2013a; Bronner et al., 2013b), sheep

115 (Hopp et al., 2007), swine (Elbers et al., 2010a) and poultry (Elbers et al., 2010b) but, to our

116 knowledge, this has never been investigated in shellfish farming. Thus, a study was conducted

117 to investigate farmers' reporting practices and behaviour, and to identify factors influencing

118 the reporting process of oyster mortality, with the ultimate aim of improving early detection

119 of

unexplained

oyster

mortality

outbreaks. 
121

122

123

124

125

126

127

128

129

130

131

132

133

134

135

136

137

138

139

140

141

142

143

144

\section{Material and methods}

\subsection{Study design and population}

The study was designed as a retrospective case-control study of oyster farmers from Charente-Maritime (France), using the oyster farmer as the epidemiological unit. CharenteMaritime is the main production region of Pacific oysters, Crassostrea gigas, in France, home to one third of all French oyster farms (Agreste, 2005). In particular, this is the main area of spat collection, supplying all the other regions with spat (Buestel et al., 2009). The study was conducted from March to December 2012.

Control farmers were randomly selected (by lottery using computer generated pseudo-random numbers) from the list of the oyster farmers who had notified authorities of at least one mortality event on their oyster production between January 2007 and December 2011 in Charente-Maritime. This list was provided by the Departmental direction for territories and sea of Charente-Maritime (i.e. the local competent authority).

Case farmers were randomly selected from the list of oyster farmers licensed for leasing grounds, run by the Departmental direction for territories and sea of Charente-Maritime, who had not notified authorities of any oyster mortality event between January 2007 and December 2011.

Only the oyster farmers farming the oyster species $C$. gigas, who were active at the time of the study and having a farm located in Charente-Maritime were considered in this study. Other shellfish farmers and oyster farmers located in other regions with leasing grounds in Charente-Maritime were excluded. 


\subsection{Sample size}

147 A sample size of 36 cases and 108 controls was calculated to provide a $95 \%$ level of 148 confidence for detecting an odds ratio of 3 with $80 \%$ statistical power, assuming a 1:3 ratio of 149 case to control farmers and a random notification process, i.e. a 50\% probability of reporting 150 observed oyster mortality. Sample size was increased by $15 \%$ to account for non-participation

151 rate observed in previous and recent studies conducted in the same population (Lupo et al., 152 2011a; Carlier et al., 2013), leading to a total of 41 cases and 124 controls, out of 165 and 703 153 eligible oyster farmers, respectively.

\subsection{Data collection}

156 Each selected farmer was sent a personally addressed letter to explain the survey objective 157 and to tell them that they would receive a telephone call. An appointment was made during 158 the telephone call to collect data. The farmer was informed about the data collection 159 procedure, which would be based on a personal face-to-face interview that would take about 16045 minutes to complete. The farmers who refused to take part were asked the reason why and were compared with those farmers who agreed to participate.

162 These interviews were based on a standardized questionnaire (Table 1) that was piloted with 163 three oyster farmers and modified according to the feedback. The questionnaire (available in 164 supplementary file) contained 28 questions (54\% closed, 7\% semi-closed and 39\% open165 ended) that collected data related to socio-demographics, farm characteristics, farming 166 practices, health history on the farm since 2007, knowledge of the oyster mortality reporting 167 system and reporting behaviour. For control farmers, 12 additional questions (4 closed, 4 168 semi-closed and 4 open-ended) collected data related to their reporting practices and attitudes.

169 The previously trained, experienced interviewers (AOA and CL) conducted the pilot 
170 interviews together to ensure standardization in interview method and all questions were

171 clarified beforehand to reduce information bias due to the interviewer. Questions were asked 172 exactly as stated in the questionnaire and only non-directive guidance was given. All the 173 interviews were recorded with the oyster farmer's authorisation.

174

175 Information on the leasing grounds (location, accessibility measured by the tide coefficient, 176 number per farm and area per farm) was obtained from the public maritime area register, run 177 by the Departmental direction for territories and sea of Charente-Maritime.

178

179 All data were entered by the two interviewers into a purpose built Microsoft@ Access 2007 180 database.

181

\subsection{Statistical data analysis}

183 All statistical analyses were conducted using SAS statistical software (version 9.3 (C) 20022010, SAS Institute Inc., Cary, NC, USA).

\subsubsection{Outcome variable}

187 As the reporting behaviour of control farmers appeared to be heterogeneous, reporting farmers

were split into two subgroups. A three-category ordered outcome variable was thus created based on the oyster farmers' reporting practices of oyster mortality: Reporting, Formerlyreporting and Non-reporting farmers. Reporting farmers were defined as farmers who had

191 always reported massive mortality outbreaks since 2008. Formerly-reporting farmers were defined as farmers who used to report observed mortality events before 2010 but who had stopped reporting since. Non-reporting farmers were defined as farmers who observed but did 
195

196

197

198

199

200

201

202

203

204

205

206

207

208

209

210

211

212

213

214

215

216

217

218

219

occurred or not were excluded from the analysis $(\mathrm{N}=4)$.

\subsubsection{Explanatory variables}

The notification process falls into three steps: occurrence of the event, its detection and its notification by the farmer. Because the objective of the present study was to evaluate the potential for improvement to incite oyster farmers to report, only the detection and notification steps were studied.

A total of 50 potential explanatory variables were considered in this study.

Qualitative data from the open-ended questions were analysed using content analysis (Franzosi, 2004) to identify thematic categories. For this purpose, all the interviews were transcribed on a dedicated thematic grid and anonymised. Each respondent's transcripts were read by both interviewers to ensure familiarity with the raw data and to identify key themes and issues. An interpretative coding of the responses was used, which was driven by the data itself and not by pre-determined categories (Franzosi, 2004). Responses were then grouped together by thematic categories. The first transcripts to be analysed were coded meticulously and subsequent interviews were coded according to the thematic categories established by the initial coding process, incorporating any additional emerging issues. Saturation was reached when no new issues were raised and previously-raised issues being repeated.

All explanatory variables were binary or ordinal apart from six which were continuous quantitative, namely: age, surface area and number of leasing grounds, average tide coefficient of leasing grounds, proportions of leasing grounds accessible even at neap and only at strong tide.

Potential explanatory variables were described in terms of frequency distribution (qualitative 
data) or median and range (quantitative data), classified by the outcome variable.

221

222

223

224

225

226

227

228

229

230

231

232

233

234

235

236

237

238

239

240

241

242

243

\subsubsection{Outcome modelling}

An ordinal logistic regression analysis was conducted to investigate factors associated with the three previously defined farmer reporting behaviours, using a continuation-ratio model (Fienberg, 1980; Dohoo et al., 2009). This model predicts (1) the probability of a nonreporting behaviour, using Equation 1, and (2) the conditional probability of a formerlyreporting behaviour, given that the farmer had already reported at least once, using Equation 2, and can be written as follows:

$$
\begin{array}{ll}
\log \frac{\pi_{1}\left(x_{i}\right)}{\pi_{2}\left(x_{i}\right)+\pi_{3}\left(x_{i}\right)}=\alpha_{1}+\beta_{1} x_{i} & \text { (Equation 1) } \\
\log \frac{\pi_{2}\left(x_{i}\right)}{\pi_{2}\left(x_{i}\right)}=\alpha_{2}+\beta_{2} x_{i} & \text { (Equation 2) }
\end{array}
$$

where $x_{\mathrm{i}}$ designates the explanatory variables, $\{\pi 1, \pi 2, \pi 3\}$ are the probabilities for the realization of each of the reporting behaviour category, respectively non-reporting, formerlyreporting and reporting behaviour, with the constraint $\pi_{1}+\pi_{2}+\pi_{3}=1$.

The effect of an explanatory variable is supposed to be heterogeneous across the reporting behaviour category transitions . An unconstrained continuation-ratio model was fitted (Cole and Ananth, 2001), producing two sets of coefficients $\left(\beta_{1}\right.$ and $\left.\beta_{2}\right)$ for the explanatory variables being investigated, one set for each of the outcome categories above the baseline, i.e. the formerly-reporting versus the Reporting farmer categories, and non-reporting versus the merged categories formerly-reporting and Reporting farmers. The exponentiated regression coefficients $\left(e^{\beta}\right)$ produced odds ratio (OR) as a measure of effect (Dohoo et al., 2009).

As sampling design was outcome-driven, the probability of a farmer being sampled was not the same for all reporting behaviour categories, leading to potentially biased results 
244 (Greenland, 1994; Scott et al., 1997). The sampling design was therefore taken into account in

245 the analysis (SURVEYLOGISTIC procedure, SAS Institute Inc.). A sampling weight was

246 applied to each observed farmer: the contribution of an observation to the calculation was

247 weighted by the inverse of the probability of it being observed (Ciol et al., 2006).

248 As sampling rates were not small enough to ignore, a finite population correction factor was

249 included in the analysis to provide valid variance estimates.

250

251 The dataset was suitably restructured to allow the fitting of two separate binary logistic

252 regressions, from which estimates of the continuation-ratio model were derived (Armstrong

253 and Sloan, 1989). A similar variable selection method was applied in both models.

254 In an initial screening step, univariate ordinal logistic regression analyses were carried out 255 separately for each explanatory variable.

256 Continuous quantitative variables were categorised according to their quartile values to 257 explore the shape of their relationship with the outcome variable. When the linearity 258 assumption was violated, their best-fitting form was determined by merging logical categories 259 or categories that reflected changes in regression estimates.

260 Based on the Wald's type 3 test, p-value for variable selection and entry into the multivariate 261 model was 0.25 . Any strong colinearity $\left(\chi^{2}\right.$ test for nominal variables, $\left.p<0.05\right)$ between 262 explanatory variables was checked, and the most significant variable or the most biologically 263 related to the outcome variable was chosen.

264 The retained variables, with $<5 \%$ missing values, were then introduced into a multivariate 265 ordinal logistic regression model fitted with a manual backward-selection procedure (Wald's 266 test, $\mathrm{p}<0.05)$. Confounding was assessed by checking that the discarded variables induced $267<20 \%$ changes in the coefficients of the other variables. Biologically plausible two-way 268 interactions of the explanatory variables in the final model were tested and retained if 
significant $(\mathrm{p}<0.05)$.

270

271

\subsubsection{Model evaluation}

272 An overall goodness-of-fit statistic pertaining to the simultaneous fitting of the two models

273 was provided by the sum of the two separate deviance statistics (Agresti, 2002), with a non-

274 significant p-value, suggesting a good fitting of the model.

275

276 Individual goodness-of-fit, i.e. predictive ability of the model, was assessed by computing its

277 overall classification performance. This was evaluated by comparing the predicted reporting

278 behaviour category (identified as the category with the highest predicted probability for each

279 farmer) with the actual reporting behaviour category. Predicted probabilities of the occurrence

280 of each outcome category were calculated, accounting for the sampling design, to allow a

281 direct

interpretation. 


\section{Results}

284

285

286

287

288

289

290

291

292

293

294

295

296

297

298

299

300

301

302

303

304

305

306

\subsection{Samples description}

Due to logistical constraints, only 139 farmers were effectively contacted, of which 31 cases and 89 controls agreed to participate in the study, representing participation rates of $84 \%$ and $86 \%$, respectively. Six cases and 13 controls refused a visit, mainly declaring lack of time. Neither farmer (gender, age) nor farm characteristics (geographical location, size, number of leasing grounds, location of the production cycle) differed significantly according to the farmer participation status.

Four case farmers did not experience any mortality event in their oyster production during the 2007-2011 period, and were consequently excluded. Of the 89 reporting farmers, $55 \%$ had always reported the observed mortality events since 2008 and $45 \%$ used to report mortality events but had stopped reporting since 2010, when mortality notification became related to eligibility for the financial compensation. Thus, the results that follow refer to 27 nonreporting, 40 formerly-reporting and to 49 reporting farmers.

The characteristics of the 116 oyster farmers interviewed are summarized in Table 2. Most of these farmers were male and older than 40 . The farms included in the samples were mostly located in the south of the production area and specialized in oyster rearing, with activities related to all production stages. Most farmers had detected mortality events between 2007 and 2011 and the control farmers had first reported a mortality event mainly in 2007 or 2008 (Table 2).

3.2. Description of farmer's practices and perceptions

3.2.1. Description of an oyster mortality event according to the farmers 
307

308

309

310

311

312

313

314

315

316

317

318

319

320

321

322

323

324

325

326

327

328

329

330

331

Most farmers described a mortality event by qualitative criteria involving different senses, such as nauseating odour, observation of empty shells or a specific noise when manipulating the oyster bags (Table 2).

Counting dead oysters to estimate a mortality rate was a common practice and a threshold value was often given to distinguish an "abnormal" mortality event from a usual one, although this varied greatly from one farmer to another.

\subsubsection{Oyster mortality reporting practices}

In total, 81 control farmers provided responses about their reporting practices. No statistically significant differences were observed between responses of formerly-reporting and reporting farmers.

The reporting process of an oyster mortality event was divided into two steps for $70 \%$ of control farmers: they first report the event and then they formally notify it. They were $59 \%$ to report to their colleagues, $35 \%$ to the Departmental direction for territories and sea and $21 \%$ to the local farmer's representatives. Other structures such as Ifremer, collective farmers' society, technical institutes or accountants were also cited, but by less than $5 \%$ of interviewed farmers. Farmers mainly report in person $(70 \%)$, by phone $(32 \%)$, or by fax $(7 \%)$.

Notification procedures were fairly well-known by the reporters. They were $60 \%(47 / 80)$ to obtain the notification sheet from the local farmer representatives, $34 \%$ from the local competent authority and $5 \%$ from their accountant. Most of them $(96 \% ; 78 / 81)$ transmitted the sheet to the local competent authority and $6 \%$ to the local farmer representatives. The notification sheet was mainly delivered to addressee in person $(60 \% ; 46 / 80)$, by postal mail $(89 \%)$, by fax $(16 \%)$ or by email $(1 \%)$.

Only 5\% (4/80) of the reporters transmitted the notification sheet the day or the following day 
332

333

334

335

336

337

338

339

340

341

342

343

344

345

346

347

348

349

350

351

352

353

354

355

356

after the mortality detection, $18 \%$ did this during the following week and $15 \%$ during the following month. Half of them (54\%) waited for the 'end of the mortality season', i.e. the end of the summer. The remainders $(9 \%)$ waited until the $31^{\text {st }}$ December of the year, which has been the deadline to submit application files for financial compensation since 2010 .

\subsubsection{Perceptions of the notification system}

Most control farmers $(70 \%$; 55/79) considered that reporting oyster mortality events was 'very simple' or 'fairly simple'. However, even if they were $83 \%(52 / 63)$ to be generally satisfied with the reporting system, 63\% (50/79) of them commented on its weaknesses: onerous data retrieval (56\%), complex procedures (46\%), time consuming procedures (30\%), impractical data transfer (10\%), and lack of guidance for filling in the notification sheet $(6 \%)$.

About 85\% (72/85) of control farmers felt 'very poorly satisfied' or 'poorly satisfied' with the information feedback about the mortality notification system; the reasons they cited were: absence of feedback (61\%), too little information received (26\%), feedback disparity between the farmers $(10 \%)$, non-transparency (4\%), lack of clarity and understanding of received information (3\%).

The aim of the mortality reporting system of early warning was unclear to oyster farmers, in all the reporting behaviour categories. Only 3\% (3/88) of the control farmers and none of the 27 case farmers knew that reporting an oyster mortality event was mandatory. The aims cited by the control farmers were: descriptive purpose (50\%) and improvement of the understanding of the mortality phenomenon (45\%), obtaining financial compensation (45\%), sanitary surveillance $(6 \%)$, and warning alert onset $(3 \%)$. The case farmers cited: descriptive purpose $(68 \%)$ and improvement of the understanding of the mortality phenomenon (58\%), 
357

358

359

360

361

362

363

364

365

366

367

368

369

370

371

372

373

374

375

376

377 Among the 89 control farmers, 40 were former reporters, i.e. they had stopped reporting the

379

380

381

and obtaining financial compensation (35\%).

"Understanding the how and the why, even if we can't do anything about it"-Case \#71

Finally, $9 \%$ of control and $10 \%$ of case farmers believed that this system was useless:

“This can't avoid the problem, knowing what is going on won't change anything”-Control \#19

\subsubsection{Reasons for under-reporting}

The main reasons for non-reporting an oyster mortality event stated by the case farmers were: the amounts of financial compensation were insufficient $(39 \% ; 9 / 23)$ or that mortality impact on their production was not sufficient enough to be reported (30\%). Some of them made the comment "It's not worth it" or "This can't avoid the problem, knowing what is going on won't change anything”-Control \#19

Another $13 \%$ believed that the mortality reporting system only concerned oyster spat. As their activity did not include this production stage, they did not feel involved in the system. They were $22 \%$ to evoke the complexity of the reporting procedures, which made them reluctant to report. Other reasons, such as feeling of state handouts, system rejection, negligence or missing information about the reporting process were stated by less than $10 \%$ of the case farmers.

oyster mortality events they observed since 2010. Only 17 of them provided direct responses to the question of the reasons to stop reporting: $47 \%$ of them believed that the amounts of financial compensation were insufficient, $24 \%$ evoked the time given to reporting, $24 \%$ no longer felt involved because of pending retirement, $12 \%$ mentioned the complexity of the 
382

383

384

385

386

387

388

389

390

391

392

393

394

395

396

397

398

399

400

401

402

403

404

405

406

system, $12 \%$ referred to the decreasing mortality impact on their production in comparison with previous years, $6 \%$ felt discouraged because of the endemic situation, and $6 \%$ rejected the whole system.

\subsection{Factors associated with the farmer reporting behaviour}

A total of 29 variables were associated $(\mathrm{p}<0.25)$ with farmer reporting behaviour in the univariate analysis, of which 13 were included in both models (Table 3). Six of these 29 variables were related to farm characteristics, 12 were related to husbandry and mortality detection practices, six were related to the oyster mortality and economic history of the farm, two were related to mortality reporting history and three were related to farmer opinions of the reporting system.

Four explanatory variables were associated with farmer reporting behaviour in each of the final models (Table 4). Compared with the combined categories of formerly or currently reporting farmers, non-reporting farmers most often had smaller farms, with less than 20 leasing grounds in Charente-Maritime, and a production cycle based in Charente-Maritime but also involving other departments. They were more likely to produce only diploid oysters and had usually not received financial compensation in the years 2007-2009, when all the other variables are held constant. Compared with reporting farmers, former reporters most often had a smaller proportion of leasing grounds that were easily accessible, made their first mortality notification in 2008, thought more often that amount of financial compensation was insufficient and usually did not feel involved in the notification system, when all the other variables are held constant. There were neither confounding effects nor interactions for any of the variables in either of the final models.

The individual effects of the risk factors are illustrated in Figure 1, where the predicted 
407 probabilities are shown stratified by the levels of the risk factors

408 The overall goodness-of-fit statistic suggested that the overall model fitted the observed data

409 well. When farmers were allocated to expected reporting behaviour categories according to

410 predicted probability, the overall correct classification probability of the model was $64 \%$

411 (74/115), with $48 \%$ of non-reporting, $75 \%$ of formerly-reporting and $65 \%$ of reporting

412 farmers correctly predicted (Table 5).

413 


\section{4. Discussion}

414 To our knowledge, this study is the first to provide insights about oyster farmers' reporting

415 practices and behaviour towards oyster mortality events, and the influencing factors.

416

417 4.1. Study validity

418 Random sampling ensured data representativity in both case and control samples. Satisfactory

419 survey participation rates were achieved and non-respondents did not systematically differ

420 from respondents, limiting selection bias. Thus, we can confidently say that the results of this

421 study reflected farmers' reporting behaviour concerning oyster mortality in Charente-

422 Maritime during the study period. However, although Charente-Maritime accounts for one

423 third of the French oyster farms (Agreste, 2005), the present results could not be extended to

424 the whole French oyster farming industry. Indeed, Charente-Maritime is the traditional region

425 for oyster farming and, with Arcachon basin, is a principal site for spat collection in France

426 (Agreste, 2005). As mortality outbreaks have mostly occurred in spat since 2008 (European

427 Food Safety Agency, 2010; Segarra et al., 2010), the farmer reporting behaviour towards spat

428 mortality may differ in other oyster farming regions that do not produce their own spat.

429

430 The well-known recommendations to ensure good data collection (Martin et al., 1987) were

431 applied to minimize information bias. The questionnaire was standardized and pilot versions

432 were tested before the study. Due to the declarative nature of the potential explanatory 433 variables, a face-to-face approach was specifically chosen to increase cooperation, 434 consistency and reliability of responses as well as data completeness.

436 The outcome status was based on the yearly official notification databases provided by the 437 local competent authority. During the interview, we further confirmed this status by checking 
whether farmers recalled having reported at least one mortality event each year during the

439

440

441

442

443

444

445

446

447

448

449

450

451

452

453

454

455

456

457

458

459

460

461

462

study period. Farmers with leasing grounds in other departments could have reported observed oyster mortality to the local competent authority of the other departments, leading to a misclassification bias, as reporters were identified through the local databases in the absence of a national one. However, none of the sampled farmers mentioned this possibility during the interviews. Therefore, misclassification bias is unlikely to have had a significant influence on the observed results.

In this study, the outcome variables modelled different levels of farmer reporting compliance from more to less compliant with the mandatory reporting of oyster mortality. Thus, the continuation-ratio model was a reasonable starting formulation, as it is designed for situations in which the ordered categories represent a longitudinal progression through stages (Ananth and Kleinbaum, 1997) and notably when individual categories of the outcome are of intrinsic interest (McCullagh and Nelder, 1989). Here, the interest lies in comparing non-reporting vs. reporting farmers, and inside the reporting category, whether reporters had stopped reporting.

However, the reporting behaviour categories were not considered to be equidistant, being a former reporter is considered more similar to being a current reporter than a non-reporter. Thus, an unconstrained continuation-ratio model was built, consisting in simultaneously fitting two separate models (Armstrong and Sloan, 1989), to allow the possibility of transition-dependent explanatory variables (Allison, 2012).

Usually, sampling designs for ordinal outcome studies are based on a cross-sectional survey or longitudinal follow-up i.e. one sample further split into different outcome categories. Here, a case-control study, based on outcome-dependent sampling where individuals are sampled depending on their outcome status and exposure information is then collected on the sampled 
463 individuals, provided data for further outcome sub-classification. Naïve fitting of a

464 continuation-ratio model under such a retrospective outcome-dependent sampling design 465 would obtain biased parameter estimations (Greenland, 1994); whereas, with multiple 466 outcome categories, coefficient estimates of the logistic regression are not modified by the 467 sampling design, the intercept of the model is. This leads to biased and inaccurate predicted 468 probabilities, as these are largely determined by the relative sample sizes for cases and 469 controls. The sampling design was therefore taken into account in the analysis.

\subsection{Reporting practices}

472 The results of this study suggested that notification procedures were well known by the

473 formerly and currently reporting farmers, a result that contrasts with those from Dutch pig 474 farmers who felt uncertainty about them (Elbers et al., 2010a). The reporting system was 475 generally well accepted. The majority of the respondents considered that reporting an oyster 476 mortality event was simple but a minority found it time consuming and complex. However,

477 farmers tended to be dissatisfied with the feedback from the reporting system, considering 478 themselves as poorly informed.

480 A misunderstanding of the aims of the reporting system was highlighted, as only $3 \%$ of the 481 reporting farmers mentioned its surveillance and early warning purposes. A confounding with 482 the financial compensation for production losses was frequent in the three reporting behaviour 483 categories. In addition, the length of time between mortality observation and reporting was very variable, only $23 \%$ of the control farmers reporting within the week following the mortality observation and most did this at the end of the summer. This lack of reactivity may 486 be explained by the misunderstanding of the aims of the mandatory notification. Delayed 487 reporting is still frequent in animal-disease surveillance systems (World Bank, 2010). Given 488 the importance of this issue for early detection of disease outbreaks in shellfish production, 
489

490

491

492

493

494

495

496

497

498

499

500

501

502

503

504

505

506

507

508

509

510 Unclear case definition can hinder disease reporting (World Bank, 2010), as for abortion in

because openness and connectivity of marine systems enhance disease spread (McCallum et al., 2004) and limit the use of classical control measures (Renault, 2009), farmers' lack of awareness about disease reporting warrants further attention. The farmers need to be better informed to encourage timely reporting of oyster mortality.

\subsection{Factors associated with farmer reporting behaviour}

While the reasons for under-reporting often differ from one animal disease surveillance system to another, a number of common factors prevail. Two main groups of factors can usually explain under-reporting: inability to report (either inability to detect the event or to access to the reporting channels) or unwillingness to report, usually related to the existence of disincentives (World Bank, 2010). In this study, two different sets of factors were identified driving a farmer's decision to report oyster mortality, pertaining to both of these two main groups.

Detection is the limiting factor more often than access to reporting channels, and is commonly the result of insufficient awareness of a disease or of its threats (World Bank, 2010). In the present study, the lack of awareness about mortality reporting was highlighted and this was suspected to occur more frequently than the inability to detect oyster mortality or to access the reporting channels, as all the non-reporters had observed oyster mortality at least once during the study period and complexity of reporting procedures was only mentioned by $22 \%$ of the non-reporting farmers.

511 livestock (Bronner et al., 2013a), or a lack of specificity of clinical signs if a particular disease

512 must be reported, such as avian influenza (Elbers et al., 2010b) or classical swine fever

513 (Elbers et al., 2010a). The regulatory oyster mortality definition is subjective and its 
514 estimation is not straightforward(European Union, 2006). In the present study, both

515 qualitative and quantitative criteria used by the oyster farmers were collected to define an 516 oyster mortality event. In particular, in the univariate analysis, counting dead oysters was 517 significantly associated with compliant farmer reporting behaviour. This variable could be 518 interpreted as an indicator of the attention farmers paid to their oysters, indicating a greater 519 watchfulness of oysters by the combined categories of formerly- or currently-reporting 520 farmers than by non-reporting farmers.

521 The model relating the probability of a non-reporting behaviour showed that the farmers

522 producing exclusively diploid oysters were seven times more likely to under-report observed 523 mortality than those producing triploid oysters. Production type highly influences husbandry 524 management practices and the attention paid to the animals. This was also identified as an 525 influencing factor for the under-reporting in the mandatory abortion notification system in 526 cattle (Bronner et al., 2013b). Farmers producing exclusively diploid oysters often obtain 527 sufficient spat resources from the sea, collecting "wild" spat in summer for free. Since the 528 1990s, hatcheries also sell oyster spat, which is either diploid or triploid, to oyster farmers 529 throughout the year (Gérard, 1994). Purchasing oysters may lead farmers to watch their 530 shellfish more closely, which increases the probability of mortality detection and, thus, 531 reporting. Effectively, although farmers raising triploid oysters did not differ farmers 532 producing only diploid oysters as regards their own characteristics nor the general items of 533 their farms, they had a tendency to visit their leasing grounds more often $(\mathrm{p}=0.08)$. They were 534 also more likely to count dead oysters $(\mathrm{p}=0.02)$.

535 The probability of a farmer under-reporting oyster mortality was higher in farms having less 536 than 20 leasing grounds, which could be considered as a proxy of the farm size. The farmers 537 owning these smaller farms often worked alone, performing all oyster farming activities 538 without any employees, which would leave them with a smaller amount of time for oyster 
539

540

541

542

543

544

545

546

547

548

549

550

551

552

553

554

555

556

557

558

559

560

561

562

563

observation, thus decreasing the probability of mortality detection and of reporting. The farmers farming with a small area were older $(\mathrm{p}<0.001)$ and were less likely to count dead oysters $(\mathrm{p}=0.03)$ than farmers having more than 20 leasing grounds. Small farm size was also reported to be associated with a lower probability of reporting abortions in cattle (Bronner et al., 2013b) and scrapie suspicion in sheep (Hopp et al., 2007).

The farmers with a production cycle located both in Charente-Maritime and other departments were six times more likely to under-report observed oyster mortality than the ones with a local production cycle. This may also indicate that splitting farming activities between different locations reduces time for observation of oysters located in Charente-Maritime, decreasing the probability of mortality detection by the farmer and, thus, reporting.

Unwillingness to report is usually related to the existence of disincentives, such as bad consequences for trade or reputation or the lack of compensation for farmers (World Bank, 2010), or lack of trust in government (Palmer, 2009; Elbers et al., 2010a; Limon et al., 2013). In the present study, none of these were stated by the interviewed farmers, as, currently, mortality notification does not lead to truly penalizing consequences for oyster farmers. However, farmers who had never received financial compensation for oyster mortality before 2010 were eight times more likely to under-report oyster mortality than farmers who had already been compensated. This clearly illustrated the incentive effect of financial compensation for French oyster farmers, as previously reported for Dutch poultry farmers (Elbers et al., 2010b) or Norwegian sheep farmers (Hopp et al., 2007) but contrasts with Dutch pig farmers (Elbers et al., 2010a). However, even though compensation mechanisms were in place, some of the interviewed farmers had stopped reporting since 2010.

In fact, awareness and willingness to report should not be considered static. In the case of 
564

565

566

567

568

569

570

571

572

573

574

575

576

577

578

579

580

581

582

583

584

585

586

587

588

endemic diseases, people can often become accustomed to a situation (World Bank, 2010).

This habituation effect may have occurred here; the farmers' motivation to report mortality may have been reduced by the lack of available and effective measures to control the spread of this emerging pathogen in open waters, leading to this infection becoming endemic (Lupo et al., 2011b).

The model relating the conditional probability of a formerly-reporting behaviour, given that the farmer had already reported oyster mortality, has shown that the farmers with a small proportion of leasing grounds that are easily accessible (i.e. even at neap tide) were four times more likely to stop reporting oyster mortality. This may indicate lassitude as regards the effort needed to regularly monitor their oysters in relation to the perceived benefit. Indeed, the probability for a farmer to stop reporting oyster mortality was higher when the farmers thought that the amount of financial compensation was insufficient, and if they did not feel involved by the reporting system. These supported the hypothesis that formerly-reporting farmers were unaware of the legal framework of shellfish disease surveillance and that they misunderstood the aims of the reporting system, confounding them with the financial compensation system.

The farmers who had first notified authorities of oyster mortality in 2008 were eight times more likely to stop reporting oyster mortality than the others. This may illustrate a lack of awareness of the legal framework of the disease surveillance, formerly-reporting farmers being mostly influenced by recent events, as 2008 is the year when severe mass mortality outbreaks occurred in spat of Pacific oyster, associated with the first description of the virus genotype OsHV-1 $\mu$ Var (Segarra et al., 2010).

These results supported the hypothesis of a habituation effect combined with a lack of awareness of the aims of the surveillance system, oyster farmers looking for the self-interest in reporting, different from early detection of a disease outbreak. Such expectations have also 
589

590

591

592

593

594

595

596

597

598

599

600

601

602

603

604

605

606

607

608

609

610

611

612

613

been identified in French cattle farmers (Bronner et al., 2013a), Bolivian livestock smallholders (Limon et al., 2013) and Dutch pig farmers (Elbers et al., 2010a).

Many programs to improve compliance with reporting duties have failed because they addressed only one reason for under-reporting, while neglecting others (World Bank, 2010). In France, since 2008, a system for financial compensation for oyster production losses was put in place and, since 2010 mortality notification has become mandatory to access to the financial compensation (French Ministry of Agriculture, 2010b). The results of the present study suggest that financial compensation was a clear incentive for farmers to report oyster mortality. Despite this, some of the farmers have stopped reporting since 2010, suggesting that financial compensation was not sufficient to sustain their motivation to report oyster mortalities, as it was observed after the H7N7 highly pathogenic avian influenza epidemic in 2003 in the Netherlands (Elbers et al., 2010b). Indeed, the challenge is to find a strategy that is not only successful, but also sustainable (Hoinville et al., 2009). As previously observed in Norwegian sheep farmers (Hopp et al., 2007), this study has identified both economic and non-economic values that influence French oyster farmers' reporting behaviour. In particular, their reporting behaviour reflected a lack of knowledge about the major issue of timely reporting oyster mortality, as half of the reporters waited the end of the summer to report. These results suggest that financial incentive is not sufficient to achieve the aim of early detection of disease, notably because it does not account for the need of a timely reporting. These also suggest that, to ensure sustainable compliance of oyster farmers with reporting duties, their concerns about non-economic values should also be considered. In particular, oyster mortality reporting could be improved by changing these attitudes through farmer education concerning the aims of a surveillance system and the great importance of their vigilance and timely reporting for the detection of potential emerging or exotic diseases in 
614 shellfish. For this, participatory approaches are needed to ensure that the system will be

615 responsive to stakeholders' needs and to increase their sense of ownership and commitment

616 towards sustaining the system (Mariner et al., 2011). In addition, studies through

617 participatory approaches about disease management in farmed marine shellfish, in particular

618 measures to mitigate the effects of diseases on production, may constitute practical means for

619 sustaining the motivation of oyster farmers to participate in the surveillance system. 
621

622

623

624

625

626

627

628

629

630

631

632

633

634

635

636

637

638

639

640

641

\section{Conclusion}

This study provided some first insights into the factors driving a farmer's decision to report oyster mortality, pertaining to inability to detect the mortality event and to unwillingness to report. Financial compensation for oyster production losses appeared to be a clear incentive for reporting, but was countered by a habituation effect, combined with a lack of awareness of the aims of the reporting system: oyster farmers sought self-interest in reporting rather than the early detection of a disease outbreak.

Results showed that both economic compensation and farmers' non-economic values and perceptions should be taken into account to improve oyster farmer reporting compliance and sustainability. These findings are relevant from an educational as well as an animal-health perspective because they indicate that oyster mortality reporting could be improved by changing attitudes through education and participatory approaches.

\section{Acknowledgements}

The authors thank the French Ministry of Agriculture for funding this research project, the Departmental Direction for Territories and Sea of Charente-Maritime for the official databases access, and the farmers for their participation in the survey.

\section{Conflict of interest statement}

None. 


\section{References}

644

645

Agreste, 2005. Recensement de la conchyliculture 2001. Direction des pêches maritimes et de 646 l'aquaculture - Service central des enquêtes et études statistiques, Paris.

647

Agresti, A., 2002. Analysis of Ordinal Categorical Data - 2nd edition. Wiley, New York.

Allison, P.D., 2012. Logistic regression for ordered categories. In: SAS Institute Inc. (Ed.), Logistic regression using SAS: Theory and Application, Second Edition. SAS Institute Inc., Cary, NC, pp. 159-188

651

Ananth, C.V., Kleinbaum, D.G., 1997. Regression models for ordinal responses: a review of 652 methods and applications. Int. J. Epidemiol. 26, 1323-1333

Armstrong, B.G., Sloan, M., 1989. Ordinal regression models for epidemiologic data. Am. J. Epidemiol. 129, 191-204

Bronner, A., Hénaux, V., Fortané, N., Calavas, D., 2013a. Identification de facteurs influençant la déclaration des avortements chez les bovins par les éleveurs et les vétérinaires. Bulletin Epidémiologique Santé animale - Alimentation. 57, 5-8

Bronner, A., Henaux, V., Vergne, T., Vinard, J.L., Morignat, E., Hendrikx, P., Calavas, D., Gay, E., 2013b. Assessing the mandatory bovine abortion notification system in France using unilist capture-recapture approach. PloS one 8, e63246

Buestel, D., Ropert, M., Prou, J., Goulletquer, P., 2009. History, Status, and Future of Oyster 662 Culture in France. J. Shellfish Res. 28, 813-820

663 Carlier, M., Prou, J., Mille, D., Lupo, C., 2013. Oyster farmers' perception of spat mortality 664 outbreaks: more a firm than a farm issue. In: Verheyen, K.L.P., Fourichon, C., and the 665 SVEPM Executive Comittee (Ed.), Proceedings of the Society for Veterinary 666 Epidemiology and Preventive Medecine, Spain, Madrid, 226-237 
Ciol, M.A., Hoffman, J.M., Dudgeon, B.J., Shumway-Cook, A., Yorkston, K.M., Chan, L., 2006. Understanding the use of weights in the analysis of data from multistage surveys. Arch. Phys. Med. Rehabil. 87, 299-303

Cole, S.R., Ananth, C.V., 2001. Regression models for unconstrained, partially or fully constrained continuation odds ratios. Int. J. Epidemiol. 30, 1379-1382

Dohoo, I., Martin, W., Stryhn, H., 2009. Modelling ordinal and multinomial data. In: McPike, S.M. (Ed.), Veterinary epidemiologic research. Canada, Prince Edward Island, Charlottetown, pp. 427-444

Dufour, B., Hendrickx, P., 2009. Epidemiological surveillance in animal health. CIRAD FAO OIE and AEEMA, France, Paris.

Elbers, A.R., Gorgievski-Duijvesteijn, M.J., van der Velden, P.G., Loeffen, W.L., Zarafshani, K., 2010a. A socio-psychological investigation into limitations and incentives concerning reporting a clinically suspect situation aimed at improving early detection of classical swine fever outbreaks. Vet. Microbiol. 142, 108-118

Elbers, A.R., Gorgievski-Duijvesteijn, M.J., Zarafshani, K., Koch, G., 2010b. To report or not to report: a psychosocial investigation aimed at improving early detection of avian influenza outbreaks. Rev. Sci. Tech. 29, 435-449

European Food Safety Agency, 2010. Scientific Opinion on the increased mortality events in Pacific oysters, Crassostrea gigas. EFSA J. 8, 1-59

European Union, 2006. Council Directive 2006/88/EC of 24 October 2006 on animal health requirements for aquaculture animals and products theref, and on the prevention and control of certain diseases in aquatic animals. L328/14

Fienberg, S., 1980. The analysis of cross-classified data. The MIT Press, Cambridge, MA.

Franzosi, R., 2004. Content analysis. In: Hardy, M., Bryman, A. (Eds.), Handbook of data analysis. Sage Publications, London. 
692 French Ministry of Agriculture, 2008. Arrêté du 4 novembre 2008 relatif aux conditions de

693 police sanitaire applicables aux animaux et aux produits d'aquaculture et relatif à la 694 prévention de certaines maladies chez les animaux aquatiques et aux mesures de lutte 695 contre ces maladies. JORF 07 novembre, 17077-17083

696

French Ministry of Agriculture, 2010a. Note de service DGAL/SDSPA/N2010-8347 du 14 697 décembre 2010 relative au modèle de déclaration de hausse de mortalité de coquillages par les conchyliculteurs à la Direction Départementale des Territoires et de la Mer (DDTM).

French Ministry of Agriculture, 2010b. Circulaire DGPAAT/SDEA/C2010-3080 et DPMA/SDAPEP/C2010-9626 du 09 août 2010 relative à l'indemnisation des pertes de récolte et des pertes de fonds en ostréiculture - Barème 2010 harmonisé sur le plan national au niveau des catégories d'animaux et des tarifs.

703

Gérard, A., 1994. Spécificités des mollusques, conditions de mise en oeuvre chez l'huître 704 creuse Crassostrea gigas à l'échelle de l'écloserie et premiers résultats de terrain. In: J. Muir and F. Sevila compilers (Ed.), International Conference "Bordeaux Aquaculture '94', Bordeaux, France, 107-121. http://archimer.ifremer.fr/doc/00000/06528/

Greenland, S., 1994. Alternative models for ordinal logistic regression. Stat. Med. 13, 1665708 1677

709

Hoinville, L.J., Ellis-Iversen, J., Vink, D., Watson, E., Snow, L., Gibbens, J., 2009.

710 Discussing the development and application of methods for effective surveillance in 711 livestock populations - report of a workshop held prior to the ISVEE conference. South 712 Africa, Durban.

713 Hopp, P., Vatn, S., Jarp, J., 2007. Norwegian farmers' vigilance in reporting sheep showing 714 scrapie-associated signs. BMC Vet. Res. 3, 34. doi: 10.1186/1746-6148-1183-1134

715 Limon, G., Lewis, E.G., Chang, Y.M., Ruiz, H., Balanza, M.E., Guitian, J., 2013. Using 716 mixed methods to investigate factors influencing reporting of livestock diseases: A case 
study among smallholders in Bolivia. Prev. Vet. Med., doi:

$718 \quad$ 10.1016/j.prevetmed.2013.1011.1004

719 Lupo, C., Ezanno, P., Arzul, I., François, C., Garcia, C., Jadot, C., Joly, J.-P., Renault, T., 720 Bareille, N., 2011a. How network analysis of oyster movements can improve surveillance 721 programs? In: Ifremer (Ed.), Réunion annuelle des laboratoires nationaux de référence 722 pour les maladies des mollusques, La Rochelle, France

723 Lupo, C., Mandard, Y.M., Arzul, I., François, C., Garcia, C., Renault, T., Bareille, N., 2011 b. 724 Space-time clustering of mortality notifications in Pacific oysters of Charente sluices, 725 France, 2008-2010. In: AEEMA (Ed.), International Conference on Animal Health 726 Surveillance, France, Lyon, 166-168

727 Lupo, C., François, C., Arzul, I., Garcia, C., Joly, J.P., Renault, T., 2012a. Défis de la 728 surveillance des maladies chez les coquillages marins en France. Epidemiol. Sant. Anim. $729 \quad 62,27-42$

730 Lupo, C., Osta Amigo, A., Mandard, Y.M., Peroz, C., Arzul, I., François, C., Garcia, C., 731 Renault, T., 2012b. Sensitivity of mortality reporting by the French oyster farmers. In, 732 Proceedings of the 13th International Symposium on Veterinary Epidemiology and 733 Economics, The Neetherlands, Maastricht, 419

734 Mariner, J.C., Hendrickx, S., Pfeiffer, D.U., Costard, S., Knopf, L., Okuthe, S., Chibeu, D., 735 Parmley, J., Musenero, M., Pisang, C., Zingeser, J., Jones, B.A., Ali, S.N., Bett, B., 736 McLaws, M., Unger, F., Araba, A., Mehta, P., Jost, C.C., 2011. Integration of participatory 737 approaches into surveillance systems. Rev. Sci. Tech. 30, 653-659

738 Martin, S.W., Meek, A.H., Willeberg, P., 1987. Veterinary Epidemiology, Principles and 739 Methods. Ames: Iowa State University Press.

740 McCallum, H.I., Kuris, A., Harvell, C.D., Lafferty, K.D., Smith, G.W., Porter, J., 2004. Does

741 terrestrial epidemiology apply to marine systems? Trends Ecol. Evol. 19, 585-591 
742

743

744

745

746

747

748

749

750

751

752

753

754

755

756

757

758

759

760

761

762

763

McCullagh, P., Nelder, J.H., 1989. Generalized Linear Models. Second Edition. Chapman and Hall, London.

Miossec, L., Allain, G., Arzul, I., François, C., Garcia, C., Cameron, A., 2009. First results of an epidemiological study on oyster (Crassostrea gigas) mortality events in France during summer 2008. In, Proceedings of the 12th International Symposium on Veterinary Epidemiology and Economics, South Africa, Durban

Palmer, S.E., 2009. Factors affecting livestock disease reporting and biosecurity practices: a study of West Australian sheep and cattle producers. PhD thesis. Australia, Murdoch University, $437 \mathrm{p}$.

Renault, T., 2009. Trends and perspectives in preventing and controlling infectious diseases in molluscs. In: T.T Nakamura (Ed.), Aquaculture Research Progress. Nova Publisher, pp. $99-126$

Scott, S.C., Goldberg, M.S., Mayo, N.E., 1997. Statistical assessment of ordinal outcomes in comparative studies. J. Clin. Epidemiol. 50, 45-55

Segarra, A., Pepin, J.F., Arzul, I., Morga, B., Faury, N., Renault, T., 2010. Detection and description of a particular Ostreid herpesvirus 1 genotype associated with massive mortality outbreaks of Pacific oysters, Crassostrea gigas, in France in 2008. Virus Res. $153,92-99$

World Bank, 2010. People, Pathogens and Our Planet. Volume 1: Towards a One Health approach for controlling zoonotic diseases. Report $\mathrm{N}^{\circ}$ 50833-GLB. Washington DC. 
764 Table 1. Summary of the content of the questionnaire used to analyse factors associated with

765 farmers' reporting practices and behaviour towards oyster mortality, Charente-Maritime,

766 France, 2012

767

768

[Table 1 here]

769

Table 2. Descriptive results for potential explanatory variables associated with farmer

770

reporting behaviour of oyster mortalities, Charente-Maritime, France, 2012

771

772

[Table 2 here]

773

Table 3. Explanatory variables for the farmer reporting behaviour retained at the univariate

774

step, Charente-Maritime, France, 2012

775

776

[Table 3 here]

777 Table 4. Final multivariate continuation-ratio logit $\operatorname{model}^{1}$ for farmer reporting behaviour

778

concerning oyster mortality, Charente-Maritime, France, 2012

779

780

[Table 4 here]

781

Table 5. Contingency table for the classification performance of the final model for reporting

782

behaviour categories

783

784

[Table 5 here]

785

786 Figure 1. Predicted probabilities ${ }^{2}$ of the three reporting behaviour categories stratified by

\footnotetext{
${ }^{1}$ Deviance $=22.34$, model d.f. $=15$, Goodness-of-fit $\chi^{2}$-test statistic p-Value $=0.10$

${ }^{2}$ Using baseline case: <20 leasing grounds in Charente-Maritime; $<25 \%$ leasing grounds accessible even at neap tide; production cycle located in Charente-Maritime and in other departments; only diploid oysters produced;
} 
787 levels of the risk factors, based on the results from an ordinal logistic regression for farmer

788 reporting behaviour concerning oyster mortality, Charente-Maritime, France, 2012

789

790

[Figure 1 here]

791

first mortality notification in 2008; no compensation received during 2007-2009; farmer did not feel involved in the notification system; and farmer thought that amount of compensation is insufficient. 
791 Table 1. Summary of the content of the questionnaire used to analyse factors associated with

792 farmers' reporting practices and behaviour towards oyster mortality, Charente-Maritime,

793 France, 2012

794

\section{Sociodemographics}

Gender, age

Membership of a collective farmer's society

Farm characteristics

Other animal species produced, level of specialization

\section{Farming practices}

Rearing cycle: place and time for spat collection and growing

Types of production

Frequency of visits to leasing grounds

\section{Oyster mortality history}

Description of a mortality event, method used for detection

Time of occurrence, type and origin of concerned oysters

Perception of financial compensation for oyster mortality

\section{Oyster mortality reporting system}

\section{Knowledge}

Mandatory aspect of the mortality notification

Reporting procedures and tools, communication tools

Reporting practices and behaviour

Regularity, reporting time, time needed

Reasons for under-reporting

\section{Attitudes toward the reporting system}

Perceived usefulness, perceived simplicity, satisfaction level with the system, with the data feedback

Perceived drawbacks, desired improvements 
Table 2. Descriptive results for potential explanatory variables associated with farmer reporting behaviour of oyster mortalities, Charente-Maritime, France, 2012

797

\begin{tabular}{|c|c|c|c|}
\hline \multirow[t]{4}{*}{ Variables and categories } & \multicolumn{3}{|c|}{ Reporting behaviour } \\
\hline & & & +8 \\
\hline & \multicolumn{3}{|c|}{ No. of responses (\%) or median [range] } \\
\hline & $\begin{array}{r}\text { Reporter } \\
(\mathrm{N}=49)\end{array}$ & $\begin{array}{r}\text { Former } \\
\text { reporter } \\
(\mathrm{N}=40) \\
\end{array}$ & $\begin{array}{r}\text { Non reporter } \\
(\mathbf{N}=27)\end{array}$ \\
\hline \multicolumn{4}{|l|}{ Characteristics of the oyster farmer } \\
\hline \multicolumn{4}{|l|}{ Gender } \\
\hline Male & $43(88)$ & $37(93)$ & $27(100)$ \\
\hline Female & $6(12)$ & $3(7)$ & $0(0)$ \\
\hline Age & $48[30-65]$ & $49[31-68]$ & 49 [29-74] \\
\hline $29-41$ years & $11(25)$ & $8(21)$ & $4(15)$ \\
\hline $41-47$ years & $11(25)$ & $9(24)$ & $8(31)$ \\
\hline $48-52$ years & $9(20)$ & $10(26)$ & $6(23)$ \\
\hline 53 and older & $13(30)$ & $11(29)$ & $8(31)$ \\
\hline \multicolumn{4}{|l|}{ Member of a collective farmer's society } \\
\hline Yes & $19(39)$ & $14(35)$ & $10(37)$ \\
\hline No & $30(61)$ & $26(65)$ & $17(63)$ \\
\hline \multicolumn{4}{|l|}{ General items related to the farm } \\
\hline Geographical location of the farm headquarters & & & \\
\hline North & $7(14)$ & $6(15)$ & $1(4)$ \\
\hline South & $42(86)$ & $34(85)$ & $26(96)$ \\
\hline \multicolumn{4}{|l|}{ Had side activity } \\
\hline Yes & $6(12)$ & $7(17)$ & $5(19)$ \\
\hline No & $43(88)$ & $33(83)$ & $22(81)$ \\
\hline \multicolumn{4}{|l|}{ Other shellfish produced } \\
\hline Yes & $6(12)$ & $5(12)$ & $3(11)$ \\
\hline No & $43(88)$ & $35(88)$ & $24(89)$ \\
\hline Farm size (total leasing area) in Charente-Maritime & 280 [26-1197] & $235[45-612]$ & 188 [6-967] \\
\hline$<200 \mathrm{~m}^{2}$ & $11(23)$ & $16(40)$ & $15(56)$ \\
\hline$\geq 200 \mathrm{~m}^{2}$ & $37(77)$ & $24(60)$ & $12(44)$ \\
\hline Number of leasing grounds in Charente-Maritime & $23[1-70]$ & $19[5-50]$ & $16[1-31]$ \\
\hline$<20$ & $15(31)$ & $22(55)$ & $21(78)$ \\
\hline$\geq 20$ & $33(69)$ & $18(45)$ & $6(22)$ \\
\hline Average tide coefficient of the leasing grounds & $65[30-84]$ & $65[32-87]$ & $64[38-82]$ \\
\hline$<55$ & $8(17)$ & $5(13)$ & $8(32)$ \\
\hline$\geq 55$ & $39(83)$ & $34(87)$ & $17(68)$ \\
\hline $\begin{array}{l}\text { Proportion of leasing grounds accessible only at } \\
\text { strong tide (tide coefficient } \geq 70 \text { ) }\end{array}$ & $56[0-100]$ & $58[14-100]$ & $69[33-100]$ \\
\hline$<60 \%$ & $33(70)$ & $27(69)$ & $11(44)$ \\
\hline$\geq 60 \%$ & $14(30)$ & $12(31)$ & $14(56)$ \\
\hline $\begin{array}{l}\text { Proportion of leasing grounds accessible even at } \\
\text { neap tide (tide coefficient }<70 \text { ) }\end{array}$ & $44[0-100]$ & $42[0-86]$ & $31[0-67]$ \\
\hline
\end{tabular}




\section{Husbandry practices}

Location of the production cycle

Only in Charente-Maritime

In Charente-Maritime and other departments

Production stages

Spat collection + farming + sending

Spat collection $+/$ - farming $+/$ - sending

Spat collection

Yes

No

Growing

Yes

$48(92)$

No

Sending

Yes

No

Spat selling

Yes

No

Oyster purchase

Yes

No

Production type

Only diploid oysters

$17(35)$

$19(48)$

$22(81)$

Triploid +/- diploid oysters

Farming technique

Off-bottom (plastic mesh bags set on trestles)

Frequency of visits to each leasing ground

More often than twice a month

Once a month

7 (14)

\section{Detecting practices of an oyster mortality}

\section{Nauseating odour}

Yes

No

Empty shells

Yes

No

Flesh in shells ${ }^{3}$

Yes

No

\footnotetext{
${ }^{3}$ In shellfish, death leads to detachment of the body (flesh) of the animal from its shell and this flesh is quickly carried away by the sea water currents. Thus, observation of flesh in the shell of the dead animal is an indicator of recent occurrence of mortality.
} 
Specific noise when manipulating oyster bags

Counting dead oysters

Yes

No

Threshold mortality \% considered abnormal $<20 \%$

\section{Mortality history of oyster production}

Mortality detection during 2008-2011

Yes

Mortality detection in 2007

Yes

No

Mortality detection in 2008

Yes

Mortality detection in 2009

Yes

No

Mortality detection in 2010

Yes

3 (6)

$1(3)$

$26(96)$

No

Yes

Oyster mortality reporting history

First notification in 2007

Yes

First notification in 2008

First notification in 2009

Yes

First notification in 2010

Yes

First notification in 2011

Yes

Economic history of the farm related to financial compensation for oyster production losses 
Compensation received during 2007-2011

Yes

$48(98)$

$35(87)$

$12(44)$

No

$1(2)$

5 (13)

$15(56)$

Compensation received during 2007-2009 (before

notification was mandatory to obtain compensation)

Yes

No

$6(15)$

Compensation received in 2007

Yes

No

Compensation received in 2008

Yes

No

Compensation received in 2009

Yes

No

Compensation received in 2010

Yes

No

Compensation received in 2011

Yes

No

\section{Perceptions towards mandatory notification of oyster mortality}

Farmer thought the notification system too complex ${ }^{4}$

True

False

Farmer did not feel involved in the notification system $^{1}$

True

False

Farmer adopted a fatalistic and discouraged attitude with regard to the current situation ${ }^{1}$

True

False

Confounded mortality notification system for surveillance with compensation system for losses ${ }^{1}$

True

False

Farmer thought the amount of compensation insufficient $^{1}$

\begin{tabular}{lrrr} 
True & $48(98)$ & $31(77)$ & $20(74)$ \\
False & $1(2)$ & $9(23)$ & $7(26)$ \\
\hline
\end{tabular}

\footnotetext{
${ }^{4}$ These variables were built transversally from the responses to different questions.
} 
799 Table 3. Explanatory variables for the farmer reporting behaviour retained at the univariate step, Charente-Maritime, France, 2012

Variables and categories

Former reporter vs. Reporters

p-Value

Non reporters vs. (Former reporters and

p-Value Reporters)

General items related to the farm

Geographical location of the farm

headquarters

South vs. North

0.285

1.06

$0.35-3.23$

0.92

$-0.746$

0.498

0.22

$0.03-1.58$

0.134

Maritime)

$<200 \mathrm{~m}^{2}$ vs. $\geq 200 \mathrm{~m}^{2}$

Number of leasing grounds

$<20$ vs. $\geq 20$

0.404

0.223

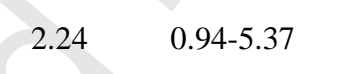

0.070

0.519

0.212

2.82

1.23-6.47

0.495

0.211

2.69

$1.18-6.14 \quad 0.019$

0.787

0.239

4.82

$1.89-12.33$

0.001

Average tide coefficient of the leasing grounds

$<55$ vs. $\geq 55$

$-0.166$

0.292

0.72

$0.23-2.25$

0.57

0.486

0.248

2.64

1.00-6.97

Proportion of leasing grounds accessible only at strong tide (tide coefficient $\geq 70$ ) $<65 \%$ vs. $\geq 65 \%$

$0.223 \quad 0.95$

Proportion of leasing grounds accessible even at neap tide (tide coefficient $<70$ ) $<25 \%$ vs. $\geq 25 \%$

\section{Husbandry practices}

Location of the production cycle

Charente-Maritime and other

departments vs. only in Charente

0.77

$0.30-2.01$

0.59

0.273

0.226

1.73

$0.71-4.18$

0.23

Maritime 
Production stages

Spat collection + farming + sending vs

0.256

0.90

$0.33-2.45$

0.84

$-0.456$

0.226

0.40

$0.17-0.97$

0.043

Spat collection

Yes vs. no

$-0.109$

0.400

0.80

0.16-3.86

0.79

$-0.573$

0.306

0.32

$0.10-1.06$

0.061

Growing

Yes vs. no

$-0.463$

0.588

0.40

0.04-3.97

0.43

$-0.803$

0.376

0.20

$0.05-0.88$

0.033

Spat selling

$-0.32$

0.444

0.09-2.99

$-0.536$

0.334

0.34

$0.09-1.27$

0.108

Oyster purchase

Yes vs. no

$-0.178$

0.204

0.70

$0.32-1.56$

$-0.672$

0.229

0.26

$0.11-0.64$

0.003

Production type

Only diploids vs, triploids + /- diploids

0.266

$0.76-3.82 \quad 0.20$

0.934

0.253

6.48

$2.40-17.48$

0.002

Detecting practices of an oyster mortality

Nauseating odour

Yes vs. no

0.049

$-0.278$

0.208

0.57

$0.25-1.30$

Flesh in shells

Yes vs. no

0.205

0.97

$0.43-2.16$

0.93

0.305

0.208

1.84

$0.81-4.16$

Specific noise when manipulating oyster

bags

Yes vs. no

$-0.114$

0.323

0.80

$0.22-2.83$

0.72

0.407

0.268

2.26

0.79-6.46

Counting dead oysters

Yes vs. no

$-0.403$

0.364

0.45

0.11-1.86

0.27

$-0.742$

0.269

0.23

0.08-0.65

0.006 
Value of the mortality \% abnormal threshold

$<20 \%$ vs. $\geq 20 \%$

$-0.099$

0.231

0.82

$0.33-2.03$

0.67

0.266

0.218

1.70

$0.72-4.01$

0.22

Notification history of oyster mortality

First notification in 2007

Yes vs. no

$-0.657$

0.267

0.27

0.09-0.77

0.014

$\mathrm{NA}^{5}$

NA

NA

NA

NA

First notification in 2008

Yes vs. no

1.010

0.235

7.53

$3.00-18.88$

$<0.0001$

NA

NA

NA

NA

NA

\section{Mortality history of the oyster production}

Mortality detection in 2008

Yes vs. no

0.744

0.528

4.43

$0.56-35.11$

0.16

$-0.439$

0.323

0.42

$0.12-1.47$

Economic history of the farm related to compensation for oyster production losses

Financial compensation received during

2007-2009

No vs. yes

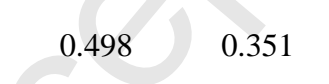

\subsection{1}

$0.68-10.71$

0.16

1.280

0.247

12.9

4.90-34.07

Financial compensation received in 2008

No vs. yes

$1.10-8.60$

0.034

1.033

0.228

7.89

$3.23-19.28$

$<0.0001$

Financial compensation received in 2009

No vs. yes

0.747

0.334

4.45

$1.20-16.47$

0.025

1.556

0.262

22.46

8.06-62.60

$<0.0001$

${ }^{5}$ Not available 
Financial compensation received in 2010

No vs. yes

0.901

0.292

6.06

$1.93-19.04$

0.002

1.561

0.283

22.68

7.49-68.62

$<0.0001$

Financial compensation received in 2011

No vs. yes

1.365

0.319

15.33

4.39-53.51

$<0.0001$

1.567

0.309

22.96

6.85-76.94

$<0.0001$

Perceptions toward mandatory notification of oyster mortality

Farmer felt the notification system was

too complex

True vs. false

0.514

0.229

$2.79 \quad 1.14-6.84$

0.025

$-0.203$

0.203

0.67

$0.30-1.47$

0.32

Farmer did not feel involved in the

notification system

True vs. false

$1.07-23.34$

0.041

0.660

0.258

3.74

$1.36-10.28$

0.011

Farmer thought the amount of

compensation insufficient 
801 Table 4. Final multivariate continuation-ratio logit model ${ }^{6}$ for farmer reporting behaviour concerning oyster mortality, Charente-Maritime,

802 France, 2012

Variables and categories

\begin{tabular}{|c|c|c|c|c|c|c|c|c|}
\hline \multicolumn{3}{|c|}{ Former reporters vs. Reporters ${ }^{7}$} & \multirow[t]{2}{*}{ p-Value } & \multicolumn{4}{|c|}{$\begin{array}{l}\text { Non-reporters vs. (Former reporters } \\
\text { and Reporters) })^{8}\end{array}$} & \multirow[t]{2}{*}{ p-Value } \\
\hline$\beta_{1}$ & $\operatorname{SE}\left(\beta_{1}\right)$ & $\mathrm{OR}_{1} \mathrm{CI}_{95}$ & & $\beta_{2}$ & $\operatorname{SE}\left(\beta_{2}\right)$ & $\mathrm{OR}_{2}$ & $\mathrm{OR}_{2} \mathrm{CI}_{95 \%}$ & \\
\hline 2.089 & 0.765 & & & -1.234 & 0.238 & & & \\
\hline & & & & 0.801 & 0.314 & 4.96 & $1.45-16.97$ & 0.011 \\
\hline
\end{tabular}

$<20$ vs. $\geq 20$

$0.724 \quad 0.325 \quad 4.26 \quad 1.19-15.20 \quad 0.026$

neap tide

$<25 \%$ vs. $\geq 25 \%$

Location of the production cycle

In Charente-Maritime and other departments vs. only

in Charente-Maritime

Production type

Only diploid oysters vs. triploid +/- diploid oysters

$\begin{array}{lll}0.724 & 0.325 \quad 4.26 \quad 1.19-15.20 \quad 0.026\end{array}$

First mortality notification in 2008

$\begin{array}{llllll}\text { Yes vs. no } & 1.063 & 0.289 & 8.37 & 2.69-26.02 & 0.0002\end{array}$

Financial compensation received during 2007-2009

period

No vs. yes

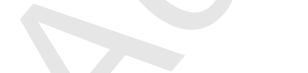

Farmer did not feel involved in the notification system

True vs. false

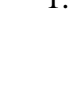

(

\footnotetext{
${ }_{7}^{6}$ Deviance $=22.34$, model d.f. $=15$, Goodness-of-fit $\chi^{2}$-test statistic - -Value $=0.10$

${ }^{7}$ Number of observations $=39$ Formerly reporting and 47 Reporting farmers, Deviance $=5.29$, model d.f. $=6$

${ }^{8}$ Number of observations $=27$ Non-reporting farmers and 86 Formerly-reporting or Reporting farmers, Deviance $=17.05$, model d.f. $=9$
} 
Farmer thought the amount of compensation

insufficient

True vs false

1.427

0.720

17.34

1.03-291.21

0.047 
804 Table 5. Contingency table for the classification performance of the final model for reporting behaviour categories

805

\begin{tabular}{lcccc} 
Observed outcome & Observed number & \multicolumn{3}{c}{ Predicted outcome category } \\
\cline { 3 - 5 } category & & Reporting farmer & Formerly-reporting farmer & Non-reporting farmer \\
\hline Reporting farmer & 48 & 31 & 17 & 0 \\
Formerly-reporting farmer & 40 & 5 & 30 & 5 \\
Non-reporting farmer & 27 & & 14 & 13 \\
\hline
\end{tabular}

806 


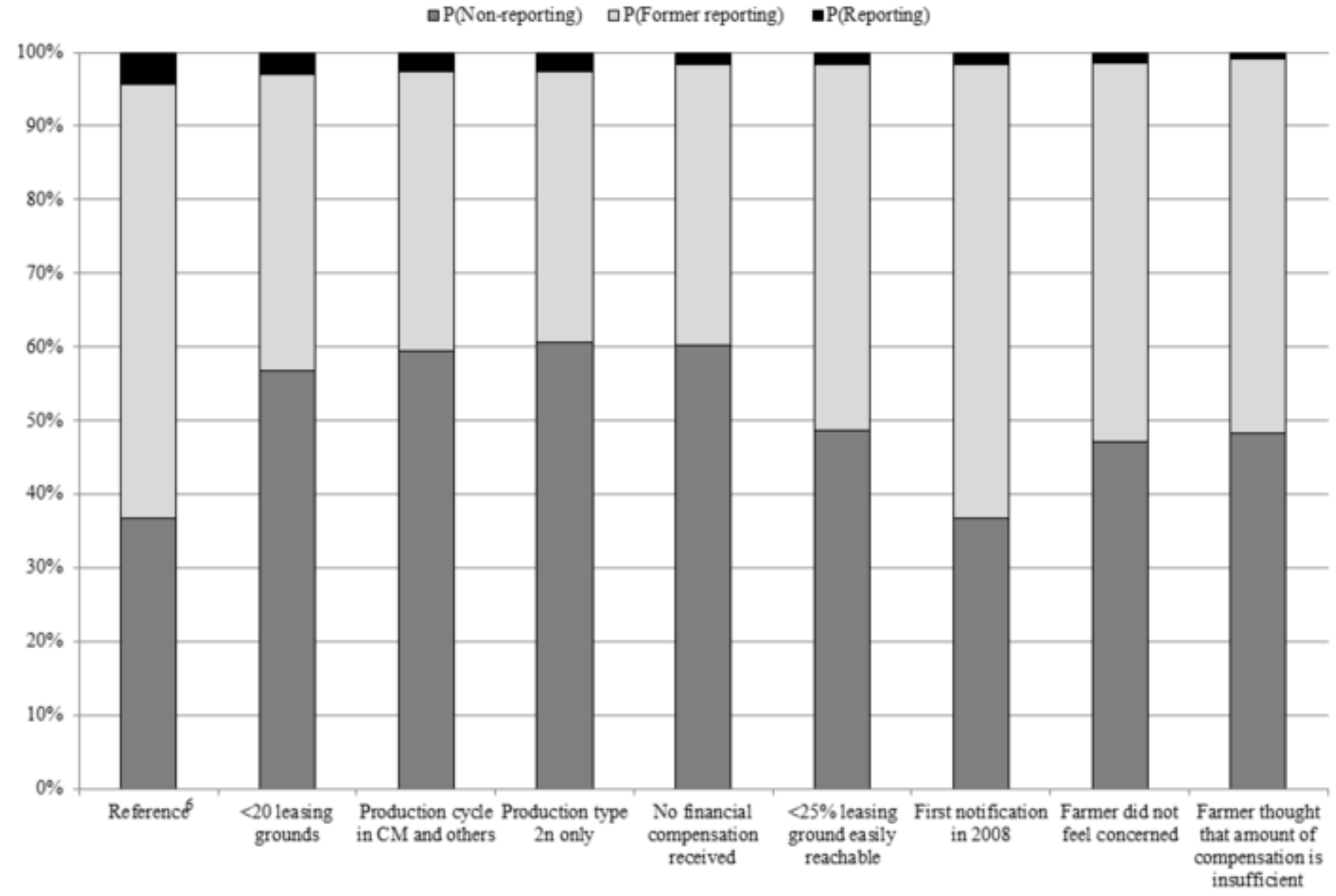

rage su ot ๖u 